\title{
ПЕРВАЯ ВСЕМИРНАЯ КОНФЕРЕНЦИЯ ПО НАРОДОНАСЕЛЕНИЮ ГЛАЗАМИ ДВУХ РУССКИХ УЧАСТНИКОВ-ЭМИГРАНТОВ
}

\section{МАРК ТОЛЬЦ}

\begin{abstract}
Публикуются сообщения С.С. Кона и А.М. Кулишера о первой Всемирной конференциии по народонаселению (Женева, 1927), появившиеся в изданиях русской послереволюционной эмиграции, которые недоступны современному читателю. Эти сообщения дополнены предисловием $и$ комментариями к их текстам. В предисловии рассказано о вкладе авторов сообщений в работу этого важного научного форума и его значении для их последующей научной деятельности. Отмечены положительные особенности публикуемых материалов в сравнении с другими сообщениями о первой Всемирной конференции по народонаселению.
\end{abstract}

Ключевые слова: история демографии, первая Всемирная конференция по народонаселению (Женева, 1927), русская послереволючионная эмигращия, Станислав Салезиевич Кон (1888-1933), Александр Михайлович Кулишер (1890-1942).

После окончания гражданской войны за пределами России вынуждено оказалась значительная часть ее интеллектуального потенциала. Известно, что представители русской эмиграции внесли большой вклад в мировую науку, плодотворно работая во многих областях знания. В демографии среди эмигрантов этой волны наиболее заметными фигурами были Александр Кулишер и Станислав Кон. Неслучайно именно они стали участниками первой Всемирной конференции по народонаселению в Женеве в 1927 г. В России до сих пор мало что известно о работе этой конференции, сыгравшей важную роль в консолидации усилий демографов, работающих в разных странах, ученые из СССР в ней не участвовали. Но российская наука была достойно представлена на ней двумя исследователями-эмигрантами.

Кон и Кулишер оставили очень важные свидетельства о первой Всемирной конференции по народонаселению в Женеве [Кон 1927а; Юниус (Кулишер) 1927], появившиеся в изданиях, давно уже ставших библиографической редкостью. Они, несомненно, заслуживают републикации, которая и предпринята нами (см. ниже).

МАРК ТОЛЬЦ (mtolts@huji.ac.il), ИЕРУСАЛИМСКИЙ УНИВЕРСИТЕТ, ИЗРАИЛЬ. (ПРЕДИСЛОВИЕ, ПОДГОТОВКА ТЕКСТОВ И ПРИМЕЧАНИЯ)

АЛЕКСАНДР КУЛИШЕР (1890-1942).

СТАНИСЛАв КОН (1888-1933).

СТАТЬЯ ПОСТУПИЛА В РЕДАКЦИЮ В СЕНТЯБРЕ 2017 Г. 
Бэкграунд этих ученых был разным, что заведомо предполагало и некоторое различие в их взглядах на работу конференции. Кон был экономистом и статистиком. Ему посчастливилось иметь таких учителей, как выдающиеся представители этих областей науки П.Б. Струве и А.А. Чупров [Дмитриев 2009]. Первой областью специализации Кулишера было правоведение, на смену которому пришла демография. Главным учителем для него в области изучения народонаселения, несомненно, был отец - М.И. Кулишер, создатель оригинальной теории миграции, которую сын творчески развивал после его смерти и уже успел к тому времени применить в изучении событий гражданской войны в России [Тольц 2014]. Кон и Кулишер представляли два основных центра русской послереволюционной научной эмиграции - пражский и парижский. Кон в Праге тесно сотрудничал с таким известным экономистом-эмигрантом, как С.Н. Прокопович. Кулишер в Париже был теснейшим образом связан с эмигрировавшим из России известным историком и политическим деятелем П.Н. Милюковым.

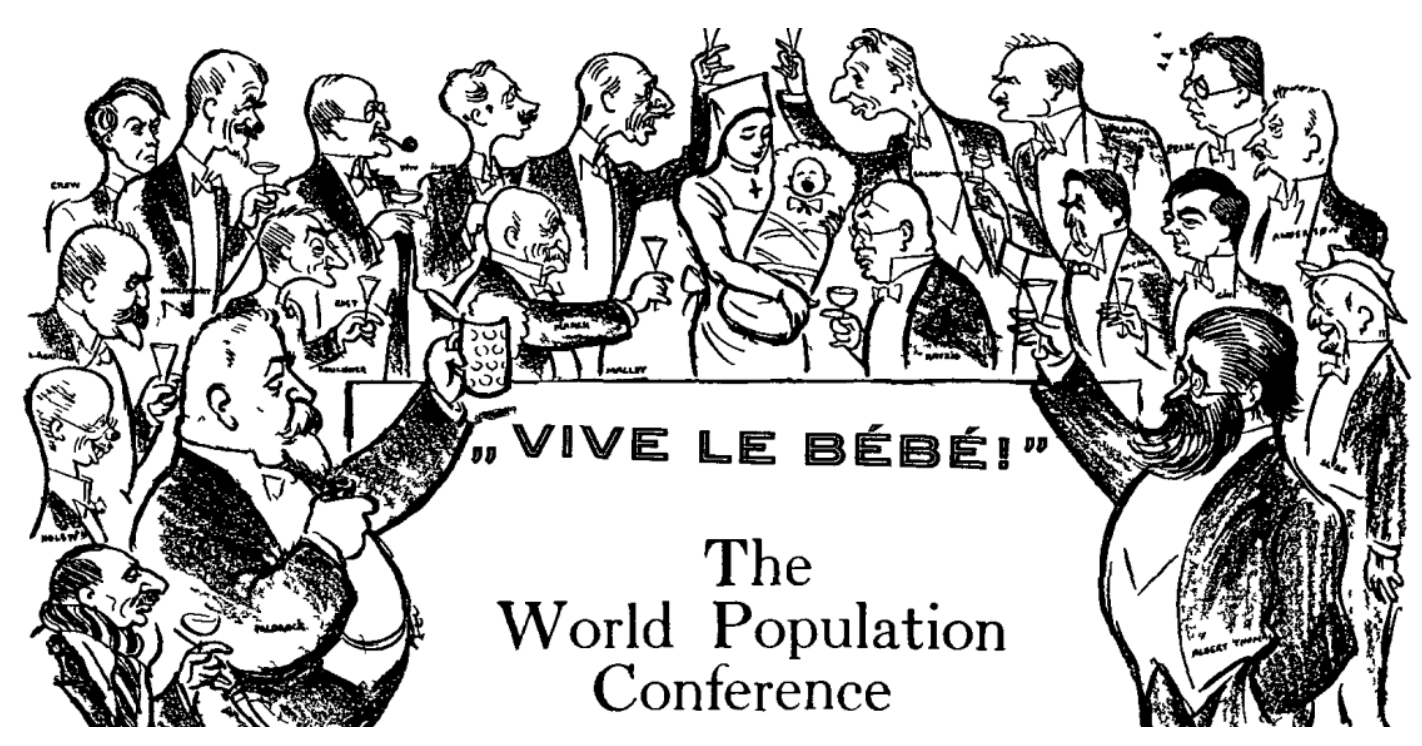

\section{Юмористическое изображение из публикации, посвященной социальной программе первой Всемирной конференции по народонаселению [Chance 1927: 291].}

Конечно, встает вопрос, на который у нас нет прямого ответа: каким могло быть общение на конференции двух ее русских участников-эмигрантов? Возможно, дальнейшая работа в архивах прольет на это определенный свет. Отметим, что их патроны - Милюков и Струве - в эмиграции были постоянными политическими оппонентами (см., например, [Яковлева 1996]). Но и Кон, и Кулишер, несомненно, были вполне самостоятельными исследователями и принадлежали к пересекающимся интеллектуальным кругам. Свидетельства этого мы находим в мемуарах С.И. Гессена, известного философа, правоведа и педагога, работавшего в это время, как и Кон, в Праге. В них он пишет, что Кулишер был «закадычным моим другом детства», непосредственные контакты, с которым продолжались до середины 1930-х годов во время приездов Гессена в Париж, где тогда жил Кулишер [Гессен 2010: 804]. Там же Гессен вспоминал, что в середине 1920-х годов при написании в Праге одной из его известных работ - «Правовое государство и социализм»- 
«очень много дали мне беседы с выдающимся экономистом и статистиком, учеником А.А. Чупрова, автором превосходного учебника статистики, изданного им по-чешски ${ }^{1},-$ C.C. Коном (S. Kohn)». Далее Гессен пишет, что и Кон стал его другом: «Я очень подружился с ним, особенно во время его продолжительной, тяжелой болезни, преждевременно сведшей его в могилу» [Гессен 2010: 796]. Когда Кон умер, именно в газете, где работал Кулишер, появился обширный некролог, написанный Гессеном [Гессен 1933].

Вклад двух русских участников-эмигрантов в работу конференции был достаточно заметным. Кон даже входил в состав ее Генерального Совета (General Council; см. [Sanger 1927: 12]). Его выступление в прениях о проблеме оптимума населения вошло в стенограмму конференции [Sanger 1927: 96-98]. В публикации ее материалов он значится представителем Чехословакии [Sanger 1927: 365]. Однако ранее в программе конференции Кон был указан как представитель России [Programme... 1927]. Причина отмеченного расхождения остается неизвестной. Зато Кулишер определенно был назван представителем России [Sanger 1927: 365]. Впрочем, один раз рядом с его фамилией в публикации материалов конференции ошибочно был указан СССР [Sanger 1927: 290]. Тремя рабочими языками конференции были английский, немецкий и французский, но все ее материалы позднее были напечатаны на английском языке. Кон выступал в прениях на французском языке. В отличие от него Кулишер свободно владел всеми тремя названными языками, его доклад о миграции [Koulisher 1927] ${ }^{2}$ и два выступления в прениях на эту тему [Sanger 1927: 102-103, 290] не потребовали перевода - они были на английском языке. Возможно, знание английского языка помогало проявлению его заметной активности на конференции.

Ведь решающая роль в организации и успешном проведении конференции принадлежала М. Сэнгер, которая возглавляла движение за планирование семьи в США [From Geneva... 1994]. Она же была редактором тома материалов конференции, напечатанного весьма быстро. Уже в мартовском номере 1928 г. журнала «Обзор контроля над рождаемостью», издававшегося движением Сэнгер, появилось объявление о том, что первые экземпляры этой книги доставлены в США из Англии, где она печаталась [Advertisement 1928]. Стоит отметить, что в этом объявлении среди немногих специально перечисленных авторов материалов конференции был назван Кулишер. Справедливость такого выделения по прошествии времени подтвердилась тем, что положения, представленные им в Женеве в 1927 г., не утратили актуальности и продолжают и сейчас привлекать внимание специалистов (см., например, [Bashford 2007]).

Естественно, что наибольшее число публикаций, посвященных различным аспектам работы конференции, появилось вскоре после ее окончания в уже упомянутом журнале Сэнгер [Chance 1927; Drysdale 1927; Haldane 1927; Observer 1927]. Публиковались такие материалы и в ведущих газетах разных стран (см., например, [Huxley 1927; Moore 1927]). Специальных демографических журналов на английском языке в то время еще не было, но

\footnotetext{
${ }^{1}$ Имеется в виду книга Кона на чешском языке «Основы теории статистического метода» [Кohn 1929].

${ }^{2}$ Необходимо отметить, что в публикациях Кулишера на разных языках написание его фамилии давалось неодинаково: Koulisher на английском, Kulischer на немецком и Koulicher на французском, а при упоминании его фамилии на этих языках в ссылках на русские тексты она часто приводится как Kulisher.
} 
сообщения о результатах конференции появились в научных изданиях, посвященных географии [Close 1927] и экономике [Carr-Saunders 1927b]. Публикация двух сообщений о работе конференции в русскоязычных изданиях стала достойным вкладом в освещение итогов конференции русской послереволюционной эмиграции.

Особую ценность в этих публикациях представляют свидетельства Кона и Кулишера о том, что не вошло в том ее материалов. Среди них надо прежде всего отметить рассказ Кулишера о регламенте конференции. В свою очередь Кон освещает некоторые важные аспекты обсуждений, отсутствующие в опубликованной стенограмме. Конечно, эти две публикации разнятся по объему и характеру изложения материала, что закономерно. Сообщение Кулишера писалось для выходившей в Париже наиболее солидной и широко читаемой газеты русского послереволюционного зарубежья «Последние новости». Его автор был явно ограничен объемом газетной площади, отведенной этому материалу. Кон опубликовал свой отчет о конференции в пражском периодическом научном издании «Русском экономическом сборнике», и у него, вероятно, не было серьезных ограничений в объеме сообщения.

Участие в конференции, несомненно, стимулировало новые исследования обоих ее русских участников. Через пять лет Кон опубликовал на английском языке свою обширную монографическую работу «Статистика естественного движения населения Европейской России во время мировой войны, 1914-1917» [Kohn 1932]. Тогда же Александр Кулишер в соавторстве с братом Евгением, тоже эмигрантом, выпустил на немецком языке книгу «Войны и миграции. Всемирная история как движение народов» [Kulischer, Kulischer 1932], которая прочно вошла в канон мировой миграциогии. Но, возможно, еще важнее то, что именно на женевской конференции Александр Кулишер впервые сформулировал свои представления о мировых демографических процессах, получившие в дальнейшем развитие в его публикациях, которые позволяют сегодня говорить о нем, как об одном из первопроходцев теории демографического перехода (см. [Вишневский, Тольц 2015]).

Публикуемые тексты приводятся в соответствии с правилами современной орфографии при сохранении основньх особенностей пунктуачии авторов. $B$ них исправлены очевидные опечатки. Написание личных имен и географических названий соответствует тому, как они были первоначально напечатаны. Все примечания, в том числе данные внутри текстов сообщений, подготовлены мною.

\section{КУДА ИДЕТ ЧЕЛОВЕЧЕСТВО?}

\section{Юниус [Кулишер А.М.]}

\section{Последние новости (Париж). 1927. 10 сентября: 3.}

Если посадить в банку пару мух: самца и самку, снабдив их определенным количеством пищи, то размножение идет сначала медленно, потом, по мере увеличения [числа] особей, все скорее и скорее; затем, с истощением запасов пищи, рождаемость уменьшается, а смертность увеличивается, пока все население банки не вымрет. Если подбавлять пищу, держа ее общие запасы на одном уровне, то и количество мух остается на одном, раз 
достигнутом, максимальном уровне. Наконец, если поставить мух в особо благоприятные условия: перегоняя взрослых мух в другую банку со свежей пищей (но в том же неизменном количестве), - так что старая банка обращается в родовспомогательное заведение для личинок, - то количество мушиного населения, рождаемость и смертность испытывают сильные колебания вверх и вниз (резкое улучшение при переходе в свежую банку, потом резкое ухудшение), но, в среднем, остается все-таки на том же раз достигнутом максимальном уровне.

Неспециалист с «сатирическим» складом ума, пожалуй, мог бы заметить, что все эти последствия можно заранее предвидеть с точки зрения «здравого смысла», и не совсем понятно, зачем их нужно еще подтверждать экспериментальным путем. Американский профессор Р. ІІирль, читавший вступительный доклад на только что закончившейся конференции по народонаселению в Женеве, держится другого мнения (см. [Pearl 1927]). Он полагает, что эти опыты иллюстрируют закон развития всякого «населения», - не только мушиного, но и всех видов живых существ, в том числе и человеческого рода. Это развитие обязательно идет по некоторой кривой, именуемой «логистической»: эта кривая поднимается сначала отлого, потом все более резко, затем достигает некоторой высшей горизонтали, на которой и останавливается совершенно. То обстоятельство, что высота этой горизонтали в данном случае была определена по воле экспериментатора, произвольно определившего количество пищи, предоставленное данному мушиному обществу, - между тем, как размер средств существования человеческого общества зависит в большей или меньшей степени от труда самого, этого общества, - не смущает докладчика. По его мнению, все возможные экономические и социальные факторы, воздействующие на развитие населения, могут быть подведены под общее понятие закона увеличивающейся тесноты, которому подвержено всякое население, развивающееся в определенном пространстве. Пройдя стадию усиливающегося размножения, определяемого чисто математическим результатом увеличения числа особей, оно подпадает под действие закона тесноты, выражающегося в уменьшении рождаемости и в увеличении смертности. Одно из этих явлений может быть ослаблено или устранено благодаря увеличению другого: напр., население может держать свою смертность на низком уровне, т.е. сохранять более длинную продолжительность жизни, если оно сдерживает свое количество в требуемом условиями размере путем низкой рождаемости. Но так или иначе оно достигнет своей «асимптоты», на которой и должно остановиться. Это утверждение Пирль подтверждал ссылками на развитие населения в Англии, Соед. Штатах и др. странах в XIX веке.

Эта, крайне рискованная, по мнению не только социологов, но и видных биологов, теория ${ }^{3}$ наметила лейтмотив конференции, в организации которой видную роль сыграли американские мальтузианцы, впрочем, привлекшие к этой организации целый ряд американских и английских ученых, авторитетность и беспристрастие которых стоят вне сомнения, а также и почти все европейские правительства. Приняли участие и финансовые силы, показавшие изумленным европейцам, как американцы умеют «делать науку».

\footnotetext{
${ }^{3}$ Современную оценку данного подхода и объяснение его весьма ограниченных возможностей см., например, [Андреев 1994].
} 
Всем приглашенным лицам было оказано поистине роскошное гостеприимство, за которое им против воли удалось дать лишь весьма небольшой эквивалент: роль большинства членов сводилась к молчаливому присутствию и лишь небольшое меньшинство получило возможность высказаться ... в течение пяти минут, а сверхпривилегированные, получившие десять минут, чувствовали себя полубогами. Впрочем, устроители были не совсем неправы, утверждая, что общение в частном порядке представителей науки разных стран может быть иногда не менее полезно, чем публичные дискуссии, и что изящная обстановка этого общения отнюдь не мешала делу.

И все же, за приятным научным и «общественным» общением чувствовался конфликт, - и не только конфликт научных мнений. Америка, не желающая терять достигнутого ею исключительно высокого уровня благосостояния масс, наглухо закрывшая свои двери перед новыми пришельцами, поставила перед всем миром вопрос: что же дальше? И сама же дала устами своих представителей, - отчасти поддержанных англичанами, - суровый ответ: да, «неограниченные возможности» XIX века кончились. Род человеческий должен сообразоваться с определившимися размерами своих, уже в значительной мере заполненных, ресурсов. Наблюдающееся повсюду в передовых странах уменьшение рождаемости есть (это, конечно, говорилось в крайне дипломатической «ученой» форме), - единственный выход из страшной грызни за место и хлеб, которая иначе была бы неизбежной. Эта мысль особенно явственно звучала в докладах проф. Ферчайльда (один из авторов американских иммиграционных скорпионов ${ }^{4}$ ) и Иста (см. [Fairchild 1927; East 1927]), утверждавших, что пищевые ресурсы земного шара могут быть увеличены лишь в малой степени, - что роль пищевых средств, независимых от сельского хозяйства, ничтожна, - и что народам нужно выбирать между численностью населения и его благосостоянием. Все эти утверждения вызывали возражения со стороны, главным образом, французских ученых, указывавших на неопределенность всей этой арифметики. Особенно резкое столкновение произошло между проф. Истом и Бурдоном, по вопросу о судьбе промышленных народов, живущих привозным хлебом. Американец утверждал, что положение этих западноевропейских народов является «искусственным» и может стать грозным, т.к. страны, вывозящие хлеб (т.е. прежде всего Сев. и Южная Америка) должны будут когда-нибудь ограничить этот вывоз в интересах своего населения. Что это, возмутился француз (см. [Bourdon 1927]), - возвращение к временам самодовлеющих государств и даже провинций; после ликвидации, свободы мирового передвижения ликвидация мировой торговли? А с другой стороны, немецкий профессор Гротъян (см. [Grotjahn 1927]) указывал, как реально происходит «приспособление количества человеческого рода». Да, передовые народы не ждут завершения спора ученых: они «приспособляются», да еще как: в Германии, которая еще недавно пугала мир своей плодовитостью, теперь, за каких-нибудь три года рождаемость упала так, что близок момент, когда должно начаться уменьшение населения. Но это «приспособление» идет своеобразным путем: поистине ужасны цифры прямого вымирания, поголовного безбрачия и бесплодия интеллигенции, чиновничества и т.д.

\footnotetext{
${ }^{4}$ Имеются в виду ограничительные американские иммиграционные законы 1921 и 1924 годов. 
Как бы то ни было, пока далеко до решения этим путем вопроса о мировых излишках населения. Первые два дня конференции, посвященные вопросу о внутренних факторах развития населения, были, как все чувствовали, только «перестрелкой». На третий день «добралась до картечи», т.е. до вопроса о переселениях. Блестящий доклад председателя международного бюро труда А. Тома был мягким и дипломатичным по форме (см. [Thomas 1927]). Осторожны были его выводы: международное урегулирование переселения в «свободные места» есть пока отдаленный идеал; сейчас нужно хотя бы устроить институт для «чисто научного» изучения этого вопроса. Но ... но пора покончить с тем положением, когда об этом вопросе боятся говорить и не дают говорить. Мы вернулись к временам, когда страны отгораживались друг от друга и ... оратор сделал паузу: «Господа, ведь дело идет о международном мире». Эта мысль была развита одним из последующих ораторов ${ }^{5}$, не связанным официальным положением и указавшим на тот факт, что большие переселения, - за исключением «свободного» XIX века, - были всегда связаны с войнами. Если теперь представители богатых стран не желают видеть у себя излишков бедных народов, то они должны изо всех сил помогать им найти средства существования у себя дома. А потом выступали представители и «богатых» и «бедных», и все сходились на том, что вопрос «нужно изучать». Но уже один этот факт, одно признание авторитетнейшим научным синклитом необходимости нарушить чреватое страшными угрозами молчание, является крупной заслугой конференции.

\section{МИРОВОЙ КОНГРЕСС ПО ВОПРОСАМ НАСЕЛЕНИЯ}

\section{C. Кон}

\section{Русский экономический сборник. Т. ХІ. Прага: Пламя, 1927: 91-102.}

31 августа -3 сентября ${ }^{6}$ состоялся в Женеве первый международный конгресс по вопросам населения, собравший со всех концов света, биологов, гигиенистов, социологов, экономистов и статистиков. Проблема населении, живо занимающая людей науки и политики уже более столетия, впервые была подвергнута обсуждению в столь компетентном и многосторонне-подготовленном международном собрании. Инициатива созыва конгресса вышла из Америки, от нескольких частных лиц, интересующихся вопросом, которые и взяли на себя труд по организации конгресса. Их инициатива нашла живую поддержку со стороны группы американских и английских биологов и статистиков, к которым они обратились, и которые составили первоначальное ядро подготовительного комитета. Во главе его стал сэр Бернард Маллет, известный английский демограф, бывший долголетний директор английского бюро по регистрации движения населения (Registrar General) и бывший президент Лондонского Королевского Статистического Общества.

\footnotetext{
5 Здесь Кулишер, не называя себя, чтобы сохранить тайну псевдонима, пишет о своем выступлении в прениях по докладу Тома (см. [Sanger 1927: 290]).

${ }^{6}$ Первое рабочее заседание конференции состоялось утром 31 августа 1927 г., что совпадает с датой указанной Коном, но открыта она была приемом, организованным вечером 30 августа [Drysdale 1927: 255]. Однако в томе материалов конференции по непонятной причине на титульном листе датой ее начала указано 29 августа 1927 г. (см. [Sanger 1927: 3]).
} 
Комитету удалось собрать в Женеве около 150 ученых ${ }^{7}$, в том числе ряд виднейших авторитетов в разных областях науки, в компетенцию которых входит, с той или иной стороны, проблема населения. Из биологов присутствовали, между прочим, Дэвенпорт (Нью-Йорк), Пэрль (Балтимора, С. Шт., он же известный статистик), Гольдшмидт (Берлин), Гексли (Лондон); из гигиенистов Бэрнар (Париж), Уэлч (Балтимора), Гротъян (Берлин); из экономистов и статистиков Ирвинг Фишер (Нью-Хэвенн, С. Шт.), Р.А. Фишер (Англия), Э. Селигман (Нью-Йорк), Джини (Рим), Марк (Париж), Кучинский (Берлин) и др. Хотя инициаторы конгресса принадлежат к неомальтузианским кругам и их главным мотивом было, по-видимому, поставить перед миром вопрос об опасностях, грозящих человечеству в связи с перенаселением нашей планеты, однако уже в докладах, представленных конгрессу (составивших довольно солидный том) (см. [Sanger 1927]) налицо довольно разнообразные точки зрения, и нельзя сказать, чтобы они давали только одностороннемальтузианское освещение вопроса (хотя в некоторых докладах эти ноты звучат сильно). Еще меньше это можно сказать о занятиях конгресса. Мальтузианские тенденции некоторой части собрания (главным образом англичан и американцев) встретили сильную оппозицию со стороны другой части собрания, главным образом французов и бельгийцев, но также и представителей других наций, в частности немцев, причем всех объединила резолюция, требующая строго-объективного и чисто научного дальнейшего изучения вопроса.

Конгресс открылся приветственной речью сэра Маллета (см. [Mallet 1927]), в которой он, останавливаясь на вопросе о цели созыва конгресса, отметил, что те, кто бы ждал от трехдневных заседаний разрешения всех или хотя бы части проблем населения, или какого-нибудь международного соглашения по этому вопросу, конечно, разочаруются. Но нельзя не верить, что углубленное обсуждение вопроса собранием специалистов из разных стран, в строго научном духе, на основе имеющегося запаса фактов и статистических данных, подвинет нас несколько к этой цели. Это будет только началом, за которым, для дальнейшего изучения вопроса, должны будут последовать другие конгрессы, в не слишком больших промежутках времени, при чем необходимо было бы создать постоянную международную организацию, которая бы следила за вопросами населения, производила и поощряла исследования, и созывала периодически конгрессы. Для обсуждения этой организационной стороны дела сэр Маллет предложил выбор небольшой комиссии, которая к концу конгресса представила бы свои конкретные предложения. Это и было сделано собранием.

В течение своих занятий конгресс подвергнул обсуждению четыре больших вопроса: 1) вопрос о некоторых общих биологических законах роста населения у живых существ и возможности распространения их на человеческие общества, 2) экономическую проблему населения и, в частности, вопрос о так называемом оптимуме населения, 3) вопрос о так называемых «дифференциальных нормах рождаемости», т.е. о различиях в той пропорции, в которой разные классы и группы населения участвуют в создании будущих поколений, 4) проблему международных миграций.

\footnotetext{
${ }^{7}$ Согласно другому источнику, всего в конференции приняло участие 200 человек [Observer 1927: 287]. 
Первому вопросу был посвящен доклад профессора Pearl'я, (которым занятия конгресса и открылись) о «биологии роста населения» (см. [Pearl 1927]). Докладчик обратил внимание конгресса на факт, установленный биологами, что у самых разнообразных организмов рост населения совершается по характерной кривой, которую докладчик, следуя бельгийскому математику Verhulst'y (говорившему о ней еще в первой половине прошлого века) называет «логистической кривой». Население растет сначала медленно, но потом все быстрее, пока рост его не достигнет стадии максимальной быстроты; после этого начинается замедление: население растет все медленнее и медленнее, и, наконец, совсем приостанавливается в своем росте. Этот процесс наблюдался в большой точности в ряде лабораторных работ над дрожжами, некоторыми бактериями, наконец, в работах, произведенных в лаборатории самого проф. Пэрля над мухой Drosophila Melanogaster, результаты которых он привел в докладе. Кроме того, статистика показывает, что в ряде стран население следовало в своем росте, поскольку это может быть установлено сравнением переписей, приблизительно той же кривой; таковы Швеция, Соединенные Штаты, Франция. Австрия, Венгрия, Италия. Норвегия, Шотландия, Сербия. Япония, Ява, Филиппины. Правда, период, за который мы располагаем данными переписей по этим странам, недостаточно велик, чтобы можно было с полной уверенностью утверждать, что рост населения человеческих обществ в точности следует указанному закону, но положение это, по мнению докладчика, очень вероятно. А в отношении местного населения Алжира, для которого имеется ряд переписей, произведенных французами, можно сказать, несомненно, что оно проделало цикл развития, в точности соответствующий «логистической кривой». Резюмируя, докладчик формулирует следующие тезисы: 1) статистика показывает, что у самых разнообразных организмов, от бактерий и дрожжевых грибков до человека, население следует в своем росте кривой определенного типа; 2) математические исследования показывают, что подобная кривая с необходимостью вытекает из некоторых простых допущений относительно влияния густоты населения на рождаемость и смертность; 3) эти допущения относительно влияния густоты населения на рождаемость и смертность экспериментально подтверждаются работами над населением мyх Drosophila Melanogaster.

Собрание отнеслось в общем с некоторой сдержанностью к этой попытке истолковать численное развитие человеческого населения как частный случай общего биологического «закона» роста населения у живых организмов ${ }^{8}$. Причем интересно, что против такого слишком прямолинейного распространения этого закона на человеческое общество протестовали сами биологи. Так, генетик Haldane из Кэмбриджского университета заметил, что если проф. Пэрль может считать, что человеческие общества, следуют в своем росте его кривой, то это только потому, что мы располагали данными лишь за сравнительно недавнее время, и притом время, исключительное в истории человечества (см. [Sanger 1927: 39-40]). Есть основание предполагать, что во времена Римской Империи имело место в определенных районах регулярное уменьшение населения, связанное с социально-экономическими причинами․․ Проф. Гольдшмидт заявил, что именно выводы

\footnotetext{
${ }^{8}$ См. примечание 3.

9 Данный пример не найден в публикации материалов конференции. Вероятно, Кон приводит его по собственной записи этого выступления.
} 
проф. Пэрля показывают, насколько следует быть осторожным в такого рода аналогиях. В человеческом обществе условия жизни индивидуума совершенно отличны от условий жизни его в мире насекомых; здесь только в крайне редких случаях увеличение или сокращение пищевых ресурсов может отражаться непосредственно на плодовитости (см. [Sanger 1927: 49]).

К биологам присоединились и статистики и экономисты. R.A. Fisher выразил и с чисто фактической стороны сомнение в том, подходит ли напр. рост населения Англии со времени имеющихся переписей под кривую проф. Пэрля (см. [Sanger 1927: 43-46]). Проф. Rappard (Женева) отметил совершенно случайный характер даты, с которой начинаются статистические сведения для Соединенных Штатов (см. [Sanger 1927: 54]). Но нужно сказать, что некоторые экономисты и социологи признавали все же, что сильная аналогия кривой проф. Пэрля с кривой роста населения ряда стран налицо и что нельзя пройти мимо этого разительного факта.

По этому поводу позволительно заметить, что аналогия внешнего вида кривой роста сама по себе отнюдь не говорит еще о приложимости соответствующего «закона» развития, предполагающего определенный причинный механизм процесса. Довольно несомненно, что причинный механизм, определяющий рост человеческого населения - другой и неизмеримо более сложный, чем у мух Drosophila Melanogaster.

Второй вопрос - об оптимальном населении - был предметом доклада Г.П. Фэрчайльда, профессора социологии Нью-Йоркского Университета (см. [Fairchild 1927]). Проф. Фэрчайльд начал с указания, что верховным критерием в проблеме населения должен быть не возможно больший рост населения, а возможно высокий уровень его жизни. Стать на эту точку зрения мешают старые укоренившиеся предрассудки, далее забота о военном превосходстве над другими нациями, религиозное усердие, стремящееся к увеличению числа верующих данной религии или секты, наконец, национальная мегаломания, считающая благом для человечества возможное распространение именно своей нации или расы. Если отбросить эти соображения, и стать последовательно на единственно правильную, по мнению докладчика, точку зрения, что вопрос о численности населения должен подчиняться критерию возможного повышения уровня жизни населения, тогда сразу же возникает вопрос об определении оптимальной численности населения, т.е. такой численности, которая в данных условиях обеспечивала бы наивысший уровень жизни населения. Ниже этой оптимальной точки мы имеем дело с недонаселением, выше ее - с перенаселением, причем докладчик отмечает, что первое является в истории случаем значительно более редким, чем второе. Определить в каждом данном случае оптимальную численность населения есть задача, нелегкая, но основная для науки о населении. Первой необходимой ступенью к такому диагнозу является анализ факторов, от которых зависит уровень жизни населения. Таких факторов докладчик находит три: 1) численность населения, 2) земля и ее плодородие, 3) то, что он называет «степенью развития искусств» (stage of arts), и что должно означать всю совокупность технических орудий, методов и познаний, прилагаемых человеческим обществом для добывания нужных ему материальных благ. Докладчик пытается анализировать связь между этими факторами, но ограничивается лишь самым общими указаниями, заключая, что во всяком случае, при 
данном уровне «искусств» и данном плодородии почвы уровень жизни может быть повышен лишь за счет сокращения численности населения ${ }^{10}$.

К докладу проф. Фэрчайльда примыкал по теме доклад профессора генетики Гарвардского университета, Э. Иста, о «населении и продовольственных ресурсах» (см. [East 1927]). Докладчик оценивает весьма пессимистически продовольственные перспективы мира, считая, что, если не предполагать каких-нибудь революционизирующих изобретений в земледельческой технике, то земля может прокормить не свыше 5 миллиардов людей, каковая цифра, при теперешней норме роста населения будет достигнута через 100 лет. Докладчик считает, что никакое усилие к повышению урожайности земли - если оно не будет сопровождаться ограничением численности населения - неспособно реально улучшить положение. - «Это бы сводилось к производству большего количества пшеницы для того, чтобы кормить большее количество людей, которые бы в свою очередь производили большее количество пшеницы и т. д.». Нельзя не отметить, что с статистической стороны доклад был обоснован довольно скупо.

В обоих этих докладах, относящихся к экономической проблеме населения и взаимно дополняющих друг друга, как видим, сильно ощущается мальтузианская тенденция; в особенности это относится к докладу проф. Иста. В прениях, общих, по обоим докладам, эта тенденция была подвергнута частью ораторов решительной критике. По поводу соображений проф. Фэрчайльда указывалось на то, что круг из четырех факторов, о которых он говорит, - уровень жизни, население, земля и «искусства» - не так уж фатально замкнут, ибо рост населения способен сам по себе вызывать рост изобретательности и технический прогресс, т.е. существенные изменения в «уровне искусств»; указывалось далее, что докладчик совершенно не учитывает «относительных» элементов в современном перенаселении, связанных с неравномерным распределением благ; далее, что современный момент в развитии населения многих стран дает основания не столько к опасениям о перенаселении, сколько, наоборот, к опасениям о недонаселении; это относится не только к Франции, где эта опасность не нова, но и к другим странам и, в особенности, к современной Германии, представители которой приводили в прениях разительные цифры, характеризующие процесс сокращения рождаемости в Германии в последние годы.

По поводу пессимистических прогнозов проф. Иста указывалось, что, с одной стороны, совершенно невозможно предвидеть те технические перемены в земледелии, которые произойдут в течение ближайших 100 лет, что, с другой стороны, население мира, в общем и целом, должно будет проявить тенденцию к замедлению роста и к стабилизации.

Особенно сильно эта противо-мальтузианская аргументация развивалась ораторами, говорившими на французском языке, - англичане и американцы скорее защищали мальтузианские позиции; это дало повод председательствовавшему на заседании проф.

10 Отметим, что в материалах конференции было опубликовано краткое изложение выступления Кона в прениях по докладу Фэрчайльда (см. [Sanger 1927: 96-98]). Более полное представление о позиции Кона дает его публикация на русском языке: [Кон 1927b]. 
Раппару к остроумному замечанию, что «люди французской речи проповедуют размножение, а люди английской речи проповедуют практику людей французской речи» ${ }^{11}$.

В чем, однако, все присутствующие были согласны, это в признании необходимости дальнейшего возможно широкого и углубленного изучения проблемы.

Третья проблема, занимавшая конгресс - «дифференциальные нормы размножения» - была освещена в целом ряде докладов, представленных профессорами Карр-Саундерсом, Гротьяном, Марком, Метхорстом и Джини (см. [Carr-Saunders 1927a; Grotjahn 1927; March 1927; Methorst 1927; Gini 1927]). В докладах собран весьма поучительный и интересный материал исследований, производившихся по этому поводу в разных странах хотя надо отметить, что мы находимся лишь в начальной стадии изучения вопроса.

Суть проблемы, как было выше отмечено, состоит в том, что, благодаря разной интенсивности размножения, разные классы и группы населения в разной степени участвуют в создании будущих поколений; отсюда неизбежность существенных изменений в составе будущих поколений с точки зрения разных психических и физических признаков. Изменения эти могут быть и благоприятными, и неблагоприятными; задача науки - по возможности их предучесть и оценить.

До сих пор наиболее изученным является вопрос о различиях в рождаемости у классов населения, различающихся по «социальному положению», главным образом по положению имущественному.

В докладе проф. Карр-Саундерса приведены интересные данные по Англии, характеризующие эти различия в отношении «социальных классов», которых английская статистика различает 8, но из которых - в виду некоторой непоследовательности в принципах классификации - для нас представляют интерес первых пять. В 1911 году семьи, в которых жена не достигла 45 летнего возраста, характеризовались следующим числом оставшихся в живых детей:

\begin{tabular}{c|c}
\hline Социальный класс & Количество живых детей в среднем на семью \\
\hline I & 1,68 \\
II & 2,05 \\
III & 2,32 \\
IV & 2,37 \\
V & 2,68 \\
\hline
\end{tabular}

Мы видим, что от высшего к низшему социальному классу (неквалифицированных рабочих) среднее количество детей, которое оставляет после себя супружество (рождения у женщин в возрасте свыше 45 лет уже более или менее редки), правильно повышается, причем у первого (высшего) класса оно составляет лишь 1,68, т.е. в среднем на целых 16\% меньше заменяемого им числа родителей.

Из этого бы вытекало, что высший класс (если бы он не пополнялся выходцами из низших классов) в течение небольшого числа поколений очень сильно должен был бы сократиться в своей относительной численности в составе населения. И ясно, что средний уровень в населении тех наследственных черт, носителем которых является высший класс

\footnotetext{
11 Это замечание не вошло в публикацию материалов конференции. 
населения должен будет понижаться. Некоторые из этих черт положительны, некоторые, наоборот, отрицательны. Бесспорно положительной чертой являются умственные способности, интеллектуальная тонкость. Здесь имеются прямые данные, свидетельствующие о том, что более интеллигентные семьи размножаются слабее: так, данные некоторых английских школьных исследований обнаруживают отрицательную корреляцию между интеллигентностью ребенка, устанавливаемою соответствующими «test'ами», и численностью детей в его семье

Приведенные в прочих докладах данные по другим странам обнаруживают подобную картину: более зажиточные группы населения и группы, занимающие более высокое социальное положение, размножаются слабее, чем менее зажиточные и низкие по социальному положению группы населения. В особенности низка рождаемость у группы высших либеральных профессий. А некоторые специальные исследования обнаруживают, что у выдающихся людей рождаемость падает до минимума.

По некоторым данным эти различия в интенсивности размножения разных классов с течением времени углубляются (так по данным проф. Карр-Саундерса в Англии в [первой] половине XIX в. их почти не было), по другим данным они ослабевают; особенно интересен случай Германии, где за последних 25 лет в некоторых городах, по которым имеются сведения, рождаемость рабочих слоев упала значительно сильнее, чем зажиточных слоев, так что нормы рождаемости тех и других сблизились (хотя еще не сравнялись). Проф. Гротьян отметил, что это падение рождаемости у германского пролетариата есть нечто совершенно новое в мировой истории (осторожнее было бы прибавить: поскольку за прежние времена имеются данные).

Интересны также различия, обнаруживаемые в рождаемости в зависимости от религии: у католиков она в общем держится на наиболее высоком уровне, но и у них она в последнее время заметно надает. Интересны также изменения в расовом составе человечества в связи с различной размножаемостью рас: германская раса определенно оттесняет по численности латинскую, а славянская - германскую и латинскую.

Я не могу излагать здесь подробнее материалов по этому вопросу, с которыми познакомился конгресс, ни содержания возникших прений; последние, кстати, мало прибавили к материалу докладов. Но одна постановка этого интереснейшего вопроса, который должен со временем привлечь самое серьезное внимание науки и политики, составляет существенную заслугу организаторов конгресса.

К этому вопросу примыкал по теме еще один доклад, заслушанный конгрессом уже в самом конце занятий, именно доклад E.D. Lidbetter'a (Лондонское Евгеническое Общество) на тему «Наследственность, болезненность и нищета» (см. [Lidbetter 1927]). Докладчик изложил результаты исследования, произведенного Лондонским Евгеническим Обществом над населением одного из районов Лондона, пользующимся общественным призрением. Всего было обследовано 2850 лиц со стороны физических и умственных недостатков и генеалогии этих недостатков в их семьях, далее со стороны рождаемости и выживания детей. Эта группа бедных образует как бы замкнутое общество, чаще всего брачущееся в своих пределах. Исследование обнаружило чрезвычайное постоянство у них умственно-дефективного типа и типа «слабо-вырожденного», отличающегося тупостью и 
апатией. Размножаемость в этой среде очень велика, значительно выше средней для английского населения, что составляет по мнению докладчика серьезную евгеническую опасность.

В прениях по докладу с разных сторон указывалось, что выводы докладчика грешат чрезмерным пессимизмом. В частности, проф. Марк (Париж) сослался на результаты своих исследований, показывающих, что размножаемость населения, пользующегося общественным призрением, ниже, чем у других классов населения (см. [Sanger 1927: 339340]). Некоторые ораторы прямо ставили докладчику вопрос, каким же путем он полагал бы нужным бороться с обнаруженной им опасностью: стерилизацией, или усилиями, направленными на поднятие этого слоя населения из нищеты? Надо отметить, что за стерилизацию докладчик не высказался, не усматривая в ней разрешения вопроса.

После заслушания еще доклада д-ра Кру (Crew) о «плодовитости и бесплодности» (см. [Crew 1927]), посвященного почти целиком биологической стороне вопроса, собрание перешло к обсуждению четвертой большой проблемы населения - проблемы миграций. С большим вниманием был заслушан доклад по этому вопросу директора Международного бюро Труда, Альберта Тома (см. [Thomas 1927]).

Докладчик отметил, что вопрос миграций теснейшим образом связан с вопросами естественного движения населения, не только потому, что миграции являются в значительной мере функцией естественных демографических процессов, но и потому, что они, в свою очередь, способны сильно влиять на эти демографические процессы, облегчая (или, наоборот, осложняя и ухудшая) то положение населения, которое складывается под влиянием его естественного роста. Более того, миграции есть та сторона проблемы населения, на которую возможно непосредственное воздействие мерами регулирования, между тем как на естественное движение населения такое воздействие несравнимо сложнее и труднее.

Останавливаясь, далее, на современном положении проблемы миграций, докладчик характеризует те существенные изменения, которые произошли в условиях, направлении и характере эмиграции в послевоенное время.

Былая свобода, с которой эмигранты передвигались в свое время, ныне подверглась существенным ограничениям; государства осуществляют все более строгий контроль над миграционными потоками. В частности, страны иммиграции ставят иммигрантам подчас чрезвычайно сильные преграды. Политика Соединенных Штатов в последние годы является здесь достаточным примером. В связи с этим, а также с некоторыми другими обстоятельствами, размеры эмиграции после войны сильно сократились по сравнению с довоенным временем. Но страны эмиграции должны искать выхода для избытка своего населения. Отсюда назревают конфликты, грозящие в будущем войнами, может быть более страшными, чем минувшая.

В настоящее время имеют место некоторые двусторонние международные соглашения, которыми государства регулируют свои взаимные отношения в области миграции. Но к этому прибегают главным образом в тех случаях, когда страна иммиграции так же заинтересована в последней, как и страна эмиграции. 
Каков же выход из этих конфликтов, в которых страны иммиграции защищают свое суверенное право вести ту демографическую политику, какую они считают нужной, а страны эмиграции защищают право на жизнь своего слишком густого населения? Нельзя ли найти мирные пути к более разумному размещению населения на поверхности земли, при котором явно недонаселенные территории не сосуществовали бы с перенаселенными? В частности, нельзя ли поставить уже сейчас вопрос о некой междугосударственной высшей инстанции, регулирующей рационально и беспристрастно миграционные потоки и решающей об открытии или закрытии границ каждого данного государства для тех или иных категорий населения?

Немедленное осуществление такого идеала, конечно, несбыточно, оно бы встретило непреодолимые трудности. Но некоторая подготовка к его реализации, в частности, подготовка умонастроения, внедрение в сознание людей необходимости и возможности мирного и разумного разрешения этих конфликтов, - могут быть уже сейчас нашей задачей. Для этого, прежде всего, необходимо признание и пропаганда некоторых простых принципов или директив, как-то: а) население имеет право выселяться и оседать вне своей страны лишь с известными условиями и с подчинением некоторым предписаниям; абсолютная свобода переселения не соответствует более условиям жизни современного мира; б) государства иммиграции должны иметь право отбора иммигрантов (осуществляемое при некотором международном контроле), ибо жизненные интересы страны не должны быть угрожаемы иммиграцией; в) интервенция некоторой международной инстанции (к которой государства примыкают свободно) с целью регулирования миграционных вопросов и конфликтов не должна почитаться нарушением суверенитета, а проявлением международного сотрудничества наций в общих интересах и т. П.

Конкретно, необходимо, прежде всего, создание международного института, научного центра, первой задачей которого было бы изучение проблем эмиграции, как в их международном, так и в национальном аспекте. Вторая задача - более деликатная, но еще более важная - состояла бы в том, чтобы, пока неосуществимо создание международной инстанции для разрешения и регулировании миграционных вопросов, указанный научный центр стремился бы приобрести необходимый авторитет, чтобы предлагать нациям средства удовлетворении потребностей и пути выхода из противоречий интересов, и, таким образом, постепенно подготовлять почву для осуществления правильного международного регулирования в этой области.

Конечно, подготовка к этому умов в ответственных политических кругах современного мира и в частности, тех, которые соприкасаются с международными учреждениями, есть вещь нелегкая. Но - кончает докладчик - «не стоит иметь международных учреждений для того, чтобы отступать назад каждый раз, когда встанет какой-нибудь крупный жизненный вопрос международного значения».

По докладу развернулись оживленные прения, в которых наметились довольно определенно два течения: более пессимистическое, видящее на пути разрешения миграционной проблемы и миграционных конфликтов чрезвычайные трудности, и более оптимистическое, считающее, что конфликты интересов здесь не столь глубоки и вопрос 
миграции есть скорее вопрос разделения труда между нациями (в особенности защищал эту точку зрения профессор Женевского Университета Л. Герш) (см. [Sanger 1927: 282-284]).

Представители стран эмиграции обрисовывали трудное положение в их странах, возникшее в связи с преградами, ставимыми в последнее время эмиграции; интересно, что лишь представитель Италии, д-р Больдрини заявил, что сокращение эмиграции не отразилось на увеличении безработицы в Италии; если последнее имеет место, то оно будто бы иного происхождения (см. [Sanger 1927: 280]).

Представители стран иммиграции (Соединенных Штатов и Франции) подчеркивали гигиенические и евгенические мотивы в миграционной политике своих правительств, указывая, что с серьезностью этих мотивов нельзя не считаться.

Идея международной инстанции, регулирующей миграционные дела, многим ораторам показалась нереальной, некоторые даже высказывали опасения, как бы научный международный центр по вопросам миграции не обострил положения. Но большинство отнеслось положительно к идее научного центра и к необходимости энергичной работы над подготовкой умонастроения к мирному разрешению миграционных проблем.

Заключительное (частное) заседание конгресса было посвящено заслушанию и обсуждению доклада выбранной в первом заседании комиссии по организационному вопросу. Признана была необходимой подготовка организации «перманентной международной унии» по вопросам населения для объективного, чисто научного изучения этих вопросов с разных сторон (в частности, с социологической и биологической) ${ }^{12}$. С этой целью был избран временный комитет из 10 лиц с правом кооптации добавочных членов. В составе комитета представлены довольно разнообразные точки зрения, разные страны и разные специальности, хотя нельзя не отметить некоторого преобладания представителей наук биологических над представителями социально-экономических наук. Надо надеяться, что временный комитет в скором времени приступит к осуществлению возложенных на него заданий.

\section{ЛИТЕРАТУРА}

Андреев Е.М. (1994). Логистическое население // Народонаселение: Энциклопедический словарь / Под ред. А.Я. Кваши и др. М.: Большая российская энциклопедия: 208-209.

Вишневский А., М. Тольц (2015). Незамеченный вклад в теорию демографического перехода // Демографическое обозрение. 2(4): 6-34. URL: https://demreview.hse.ru/2015-4/179982792.html (дата обращения: 13.12.2017).

Гессен С.И. (1933). С.С. Кон // Последние новости (Париж). 21 февраля: 2.

Гессен С. И. (2010). Избранное. М.: РОССПЭН. 960 с.

12 В результате в 1928 г. был создан Международный союз по научным исследованиям проблем народонаселения, преобразованный в 1947 г. в Международный союз по научным исследованиям в области народонаселения [IUSSP 2017]. 
Дмитриев А.Л. (2009). Кон Станислав Салезиевич // Общественная мысль Русского зарубежья. Энциклопедия / Отв. ред. В.В. Журавлев. М.: РОССПЭН: 354-356.

Кон С. (1927a). Мировой конгресс по вопросам населения // Русский экономический сборник. XI. Прага: Пламя: 91-102.

Кон С. (1927b). К вопросу об оптимуме населения // Русский экономический сборник. XI. Прага: Пламя: 103-112.

Тольц М. (2014). Вклад семьи Кулишеров в мировую миграциологию // Демоскоп Weekly. 603-604. URL: http://demoscope.ru/weekly/2014/0603/nauka04.php (дата обращения: 13.12.2017).

Юниус [Кулишер А.М.] (1927). Куда идет человечество? // Последние новости (Париж). 10 сентября: 3.

Яковлева Т.А. (1996). Пути возрождения. Идеи и судьбы эмигрантской печати П.Б. Струве, П.Н. Милюкова и А.Ф. Керенского. Иркутск: Издательство ИГЭА. 216 с.

[Advertisement] (1928): Just received from England! // Birth control review. 12(3): 98.

Bashford A. (2007). Nation, empire, globe: the spaces of population debate in the interwar years // Comparative studies in society and history. 49(1): 170-201.

Bourdon J. (1927). Is the increase in the population a real danger for the food supply of the world? // Sanger M., ed. Proceedings...: 111-113.

Carr-Saunders A.M. (1927a). Differential fertility // Sanger M., ed. Proceedings...: 130-143.

Carr-Saunders A.M. (1927b). The population conference at Geneva // The economic journal. 37(148): 670-672.

Chance J. (1927). The world population conference - the social programme // Birth control review. 11(11): 291, 310.

Close C.F. (1927). The world population conference of 1927 // The geographical journal. 70(5): 470-472.

Crew F.A.E. (1927). Concerning fertility and sterility in relation to population // Sanger M., ed. Proceedings...: 214-233.

Drysdale C.V. (1927). The first world population conference: some impressions // Birth control review. 11(10): 255-256, 278.

East E.M. (1927). Food and population // Sanger M., ed. Proceedings...: 85-92.

Fairchild H.P. (1927). Optimum population // Sanger M., ed. Proceedings...: 72-85.

From Geneva to Cairo: Margaret Sanger and the first world population conference (1994) // The Margaret Sanger papers project newsletter. URL:

https://www.nyu.edu/projects/sanger/articles/from_geneva_to_cairo.php (дата обращения: 13.12.2017).

Gini C. (1927). Some Italian enquiries into differential reproductivity // Sanger M., ed. Proceedings...: 157-169.

Grotjahn A. (1927). Differential birth rate in Germany // Sanger M., ed. Proceedings...: 149-157.

Haldane C. (1927). More impressions of the conference // Birth control review. 11(10): 257-258.

Huxley J. (1927). Too many people seen as real world danger // The New York Times. 16

October: 6. 
IUSSP (2017). The history of the IUSSP // IUSSP website. URL: https://www.iussp.org/en/about/history (дата обращения: 13.12.2017).

Kohn S. (1929). Základy teorie statistické metody. Praha: Nakl. Státního úřadu statického. 483 p.

Kohn S. (1932). The vital statistics of European Russia during the world war 1914-1917 // The cost of the war to Russia. New Haven: Yale University press: 1-154.

Koulisher A. (1927). Some aspects of the migration problem // Sanger M., ed. Proceedings...: 305-309.

Kulischer A., E. Kulischer (1932). Kriegs- und Wanderzüge. Weltgeschichte als Völkerbewegung. Berlin - Leipzig: Walter de Gruyter.

Lidbetter E.D. (1927). Heredity, disease and pauperism // Sanger M., ed. Proceedings...: 326334.

Mallet B. (1927). Opening address // Sanger M., ed. Proceedings...: 17-19.

March L. (1927). Differential increase in the population in France and in the world // Sanger M., ed. Proceedings...: 143-148;

Methorst H.W. (1927). Results of differential birth rate in The Netherlands // Sanger M., ed. Proceedings...: 169-190.

Moore E. (1927). The world population conference // The Spectator (London). 9 September: 8.

Observer (1927). The world population conference - international aspects // Birth control review. 11(11): 287-288.

Pearl R. (1927). Biology of population growth // Sanger M., ed. Proceedings...: 22-38.

Programme of world population conference (1927) // Birth control review. 11(10): 251.

Sanger M., ed. (1927). Proceedings of the World population conference. London: Edward Arnold. 383 p.

Thomas A. (1927). International migration and its control // Sanger M., ed. Proceedings...: 256265. 


\title{
THE FIRST WORLD POPULATION CONFERENCE THROUGH THE EYES OF TWO RUSSIAN EMIGRANT PARTICIPANTS
}

\section{MARK TOLTS}

\begin{abstract}
This publication provides Stanislas Kohn's and Alexander Kulischer's overviews of the first World Population Conference (Geneva, 1927). The authors of the overviews were Russian post-revolutionary émigrés, whose publications are now almost inaccessible to contemporary readers. A preface and helpful explanations have been added to the overviews. The preface highlights the contribution of the authors of the overviews to the work of the conference and shows the significance of the conference for their later scholarly efforts. The positive features of the published materials are noted in comparison with some other reports on the first World Population Conference.
\end{abstract}

Key words: history of demography, the first World Population Conference (Geneva, 1927), Russian postrevolutionary emigration, Stanislas Kohn (1888-1933), Alexander Kulischer [Koulisher] (1890-1942).

\footnotetext{
MARK TOLTS (mtolts@huji.ac.il), HEBREW UNIVERSITY OF JERUSALEM, ISRAEL.

(PREFACE, PREPARATION OF THE TEXT FOR PUBLICATION AND COMMENTS)
}

Alexander Kulischer [KOUlisher] (1890-1942).

STANISLAS KOHN (1888-1933).

DATE RECEIVED : SEPTEMBER 2017.

\section{REFERENCES}

[Advertisement] (1928): Just received from England! // Birth control review. 12(3): 98.

Andreev E.M. (1994). Logisticheskoe naselenie [Logistic population] // Narodonaselenie [Population]. Entsiklopedicheskiy slovar' [Encyclopedic dictionary] / A.Ya. Kvasha et al., eds. Moscow: Bol'shaya rossiyskaya entsiklopediya: 208-209.

Bashford A. (2007). Nation, empire, globe: the spaces of population debate in the interwar years // Comparative studies in society and history. 49(1): 170-201.

Bourdon J. (1927). Is the increase in the population a real danger for the food supply of the world? // Sanger M., ed. Proceedings...: 111-113.

Carr-Saunders A.M. (1927a). Differential fertility // Sanger M., ed. Proceedings...: 130-143.

Carr-Saunders A.M. (1927b). The population conference at Geneva // The economic journal. 37(148): 670-672.

Chance J. (1927). The world population conference - the social programme // Birth control review. 11(11): 291, 310 .

Close C.F. (1927). The world population conference of 1927 // The geographical journal. 70(5): 470-472.

Crew F.A.E. (1927). Concerning fertility and sterility in relation to population // Sanger M., ed. Proceedings...: 214-233. 
Dmitriev A.L. (2010). Kon Stanislav Salezievich [Kohn Stanislav Salezievich] // Obshchestvennaya mysl' Russkogo zarubezh'ya [Social thought of Russia abroad]. Entsiklopediya [Encyclopedia] / V.V. Zhuravlev, ed. Moscow: ROSSPEN: 354-356.

Drysdale C.V. (1927). The first world population conference: some impressions // Birth control review. 11(10): 255-256, 278.

East E.M. (1927). Food and population // Sanger M., ed. Proceedings...: 85-92.

Fairchild H.P. (1927). Optimum population // Sanger M., ed. Proceedings...: 72-85.

From Geneva to Cairo: Margaret Sanger and the first world population conference (1994) // The Margaret Sanger papers project newsletter. URL:

https://www.nyu.edu/projects/sanger/articles/from_geneva_to_cairo.php (дата обращения: 13.12.2017).

Gini C. (1927). Some Italian enquiries into differential reproductivity // Sanger M., ed. Proceedings...: 157-169.

Grotjahn A. (1927). Differential birth rate in Germany // Sanger M., ed. Proceedings...: 149-157.

Haldane C. (1927). More impressions of the conference // Birth control review. 11(10): 257-258.

Hessen S.I. (1933). S.S. Kon [S.S. Kohn] // Poslednie novosti (Paris) [The latest news (Paris)]. 21 February: 2.

Hessen S.I. (2010). Izbrannoye [Selected works]. Moscow. ROSSPEN. 960 p.

Huxley J. (1927). Too many people seen as real world danger // The New York Times. 16 October: 6.

IUSSP (2017). The history of the IUSSP // IUSSP website. URL: https://www.iussp.org/en/about/history (дата обращения: 13.12.2017).

Junius [Kulisher A.M.] (1927). Kuda idet chelovechestvo? [Where is humankind heading?] // Poslednie novosti (Paris) [The latest news (Paris)]. 10 September: 3.

Kohn S. (1927a). Mirovoy kongress po voprosam naseleniya [The world population conference] // Russkiy ekonomicheskiy sbornik [Russian economic collection]. XI. Prague: Plamya: 91102.

Kohn S. (1927b). K voprosu ob optimume naseleniya [On the question of the optimum population] // Russkiy ekonomicheskiy sbornik [Russian economic collection]. XI. Prague: Plamya: 103-112.

Kohn S. (1929). Základy teorie statistické metody. Praha: Nakl. Státního úřadu statického. 483 p.

Kohn S. (1932). The vital statistics of European Russia during the world war 1914-1917 // The cost of the war to Russia. New Haven: Yale University press: 1-154.

Koulisher A. (1927). Some aspects of the migration problem // Sanger M., ed. Proceedings...: 305-309.

Kulischer A., E. Kulischer (1932). Kriegs- und Wanderzüge. Weltgeschichte als Völkerbewegung. Berlin - Leipzig: Walter de Gruyter.

Lidbetter E.D. (1927). Heredity, disease and pauperism // Sanger M., ed. Proceedings...: 326334.

Mallet B. (1927). Opening address // Sanger M., ed. Proceedings...: 17-19.

March L. (1927). Differential increase in the population in France and in the world // Sanger M., ed. Proceedings...: 143-148; 
Methorst H.W. (1927). Results of differential birth rate in The Netherlands // Sanger M., ed. Proceedings...: 169-190.

Moore E. (1927). The world population conference // The Spectator (London). 9 September: 8.

Observer (1927). The world population conference - international aspects // Birth control review. 11(11): 287-288.

Pearl R. (1927). Biology of population growth // Sanger M., ed. Proceedings...: 22-38.

Programme of world population conference (1927) // Birth control review. 11(10): 251.

Sanger M., ed. (1927). Proceedings of the World population conference. London: Edward Arnold. 383 p.

Thomas A. (1927). International migration and its control // Sanger M., ed. Proceedings...: 256265.

Tolts M. (2014). Vklad sem'i Kulisherov v mirovuyu migratsiologiyu [The Kulisher family's contribution to the world migration studies] // Demoscope Weekly [Demoscope Weekly]. 603-604. URL: http://demoscope.ru/weekly/2014/0603/nauka04.php (accessed: 13.12.2017).

Vishnevsky A., M. Tolts (2015). Nezamechennyy vklad v teoriyu demograficheskogo perekhoda [An unnoticed contribution to demographic transition theory] // Demograficheskoe obozrenie [Demographic Review]. 2(4): 6-34. URL: https://demreview.hse.ru/2015--4/179982792.html (accessed: 13.12.2017).

Yakovleva T.A. (1996). Puti vozrozhdeniya. Idei i sud'by emigrantskoy pechati P.B. Struve, P.N. Milyukova i A.F. Kerenskogo [Ways of rebirth. Ideas and the fate of the emigrant press of P.B. Struve, P.N. Milyukov and A.F. Kerensky]. Irkutsk: Izdatel'stvo IGEA. 216 p. 